\title{
Innovation in additive manufacturing of parts from aluminium matrix composites
}

\author{
Tatiana Tarasova ${ }^{1}$, Galina Gvozdeva ${ }^{1}$, and Riana Ableyeva ${ }^{1, *}$ \\ ${ }^{1}$ Moscow State University of Technology Stankin, Moscow, Russia
}

\begin{abstract}
The laser build-up cladding is a well-known technique for additive manufacturing tasks. Modern equipment for the laser cladding enables material to be deposited with the lateral resolution of about $100 \mu \mathrm{m}$ and to manufacture miniature parts. In this paper the laser micro cladding process was investigated to produce miniature thin-wall parts of Al-based composites. Thin walls formation process by subsequent single tracks overlapping with vertical increment was investigated. The influence of the cladding parameters on the minimal width and the quality of the fabricated thin walls was examined. The thin walls with the minimal width of $140 \mu \mathrm{m}$ and surface roughness Ra 1,5 $\mu \mathrm{m}$ were generated. Laser micro cladding potential to manufacture lattice-shaped structures of Al-Si composites was shown. Fabricated thin-wall structures can have application in different fields e.g. aviation, automotive and tooling industries.
\end{abstract}

\section{Introduction}

3D laser metal deposition (LMD) based on the laser cladding is an established technique for direct fabrication. New laser sources like fiber and disk lasers offer the possibility to produce LMD structures smaller than $100 \mu \mathrm{m}$ wide. In the last years much effort has been made to downscale the LMD process [1-3]. The micro LMD can compete with selective laser melting in the production of miniature parts.

In case of micro LMD the laser spot diameter is comparable to the size of the build up object construction feature, which in the process of direct laser deposition act as a substrate and determines the heat dissipation conditions. The dimensional changes during build up can lead to geometrical changings of clad track. That should be taken into account during object build up by single tracks overlapping by regulating cladding parameters. But to solve this problem theoretical forecasting is un-efficient because of a lack of information about heat and mass transfer occurred in extremely nonequilibrium micro LMD conditions. The last one makes it extremely important to obtain experimental data about micro LMD process, including those necessary for the validation of computational models.

The choice of research material needs particular attention, which thermal-physical properties have to be predictable with known assumptions to compare experimental and theoretical data. In addition, material should have a high complex of physical and mechanical properties and the potential commercialization.

\footnotetext{
${ }^{*}$ Corresponding author: riana_abl@ mail.ru
} 
This work describes the results of micro LMD experimental investigation to produce thin wall 3D-objects from aluminum matrix composites (AMC).

\section{Experimental procedure}

Experiments on fabrication 3D-objects were carried out on specially equipped laser micro cladding system. The system configuration described in detail in [4]. This configuration enables to clad material of about $100 \mu \mathrm{m}$ in area.

$\mathrm{Al}-\mathrm{Si}$ powders, material of which is Al-matrix composite with reinforced $\mathrm{Si}$ particles, were used as initial cladding material. Thermal-physical properties of this material can be estimated with sufficient accuracy with known assumptions, so that it is possible to use obtained experimental data to validate computational models.

The micro LMD was conducted with powders of 2 fractions $\left(d_{50}=35 ; 45 \mu \mathrm{m}\right)$, that are corresponding to transition interval between laser cladding and laser microcladding. The maximum powder size is limited by the requirement for the minimum width of the cladding track. The minimum size of the powder is determined by the ensuring satisfactory properties condition of argon fluidization and according to the Geldart diagram [5].

Thin walls objects were fabricated by subsequent single tracks overlapping with vertical increment $\Delta \mathrm{z}$ according to scheme shown in fig (Fig. 1).
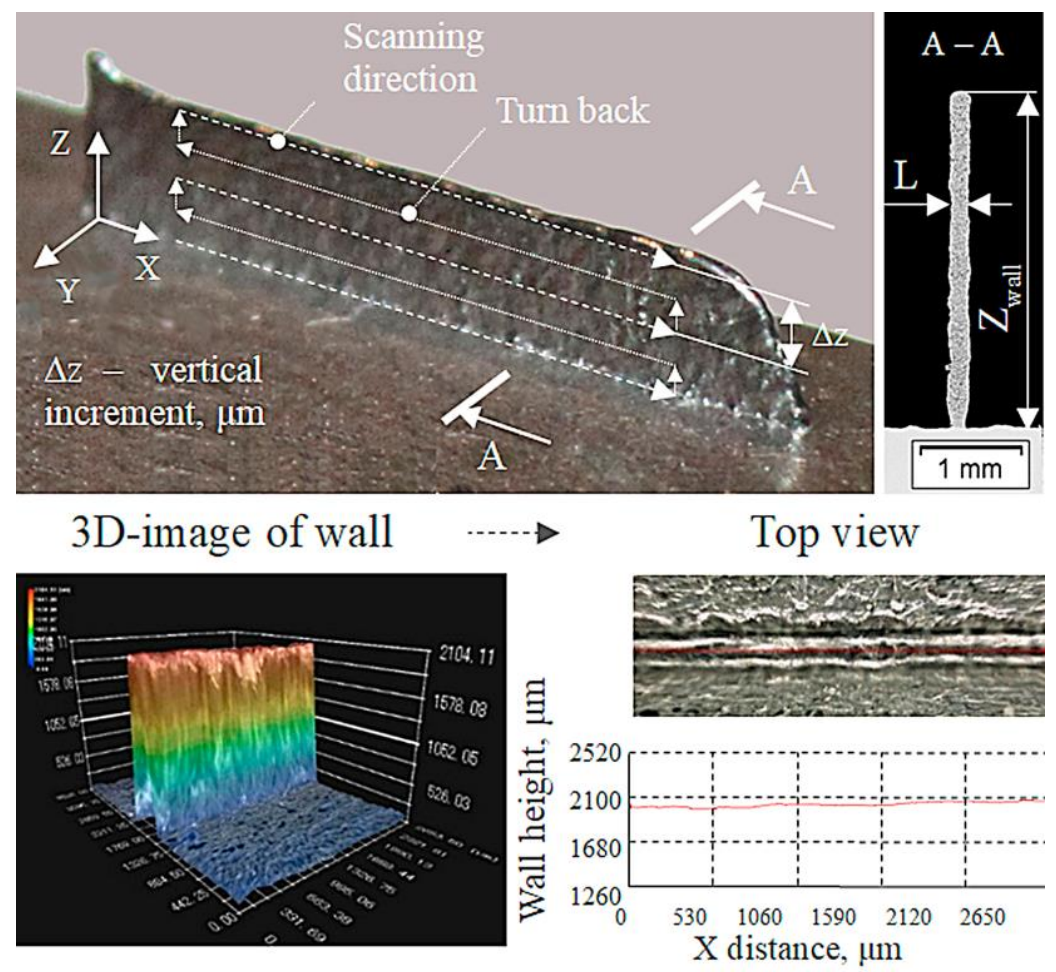

Fig. 1. Method of obtaining and investigating the quality of thin walls.

To assess the thin walls quality the following criteria were used:

- $\quad$ Minimum wall width $\mathrm{L}, \mu \mathrm{m}$

- $\quad$ Surface roughness, Ra, $\mu \mathrm{m}$

- Relative arithmetic average profile deviation. 
First the wall width was measured by micrometer Schut (Schut Geometrical Metrology, Holland) with full scale range $0 \ldots 200 \mathrm{~mm}$ and scale division $0,001 \mathrm{~mm}$. Precise measurements were taken using metallographic sections, obtained in different positions along the wall length. Afterwards the average value and mean square deviation were found.

Sidewall roughness was determined using profilograph-profilometer HOMMEL TESTER T800 (Hommelwerke GmbH, Germany) and Perthometer M1 (Mahr GmbH, Germany) on the reference line length $1,75 \mathrm{~mm}, 5,6 \mathrm{~mm}$ and $17,5 \mathrm{~mm}$.

In case of part manufacturing using LMD, as cladded layer is a substrate surface for the next layer. By thin wall (single track wide) manufacturing, underlayer condition is very essential for cladding process results. In case of adverse conditions the single tracks overlapping can be accompanied by accumulation of the upper edge linearity deviation (and, as a consequence, the product accuracy loss) and process stability violation. To investigate the wall upper edge linearity the wall profile along the cladding direction $\mathrm{Z}(\mathrm{x})$ was reproduced with a digital microscope Keyence VHX-600 (Keyence, Germany). This microscope allows to make a 3D-image of the object and to make measurements with an accuracy of $\pm 0.1 \mu \mathrm{m}$. The wall profile irregularity $Z(x)$ accumulates with increasing layers number. To assess them in addition to the standard surface roughness indicators, the profile relative arithmetic mean deviation was determined:

$$
\widetilde{R_{a}}=R_{a} / Z \cdot 100 \%,
$$

Where $\mathrm{Z}$ is the wall profile height, $\mu \mathrm{m}$.

\section{Results and discussion}

\subsection{Effect of the particle size}

Particle size effect was investigated through preliminary experiments. It was found that with increasing the particle size the parameter window narrows and shifts towards the higher power density values (the ratio of the power to the laser spot area) and the powder deposition density (the ratio of the powder mass flow to the scanning speed and the laser spot diameter). The stable tracks production from the powder with a fraction $d_{50}=45 \mu \mathrm{m}$ requires a power density of at least $75 \mathrm{~kW} / \mathrm{mm}^{2}$ and a powder deposition density of up to $0.025 \mathrm{~g} / \mathrm{mm}^{2}$. For fine powder, the power density varies over a wide range: $44.5 \ldots 70 \mathrm{~kW} /$ $\mathrm{mm}^{2}$. The powder deposition density decreases to $(0.143 \ldots 3.125) \cdot 10^{-3} \mathrm{~g} / \mathrm{mm}^{2}$.

The observed phenomena are consistent with the study results of the steels micro LMD process [6], where changes in cladding parameters are associated with the energy distribution in the "powder-substrate" system: with increasing the powder fraction, the relative powder absorbed energy fraction decreases. A lot of radiation is required to melt this powder completely.

The experiment results show the relationship between the powder fraction, track width and deposition surface quality (Fig. ). The minimum track width increases with fraction increase. At the same time, the surface quality decreases.

Reduction of the powder absorbed energy leads to appearance of unmelted particles in the flow of a gas-powder mixture that mechanically act on the molten metal. The obtained results allow to choose the most suitable powder size $d_{50}=35 \mu \mathrm{m}$ for micro LMD. 

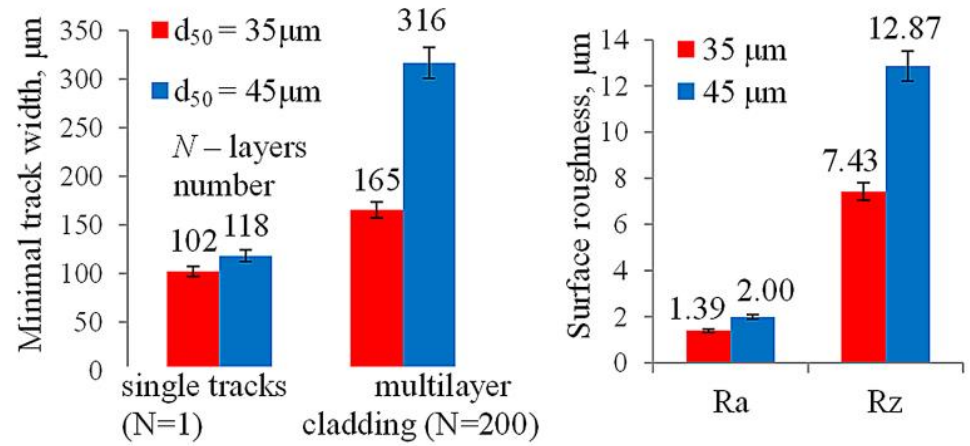

Fig. 2. Effect of the particle size on the minimal track width (lieft) and surface roughness (right).

\subsection{Effect of parameters}

The main micro LMD parameters for cladding single tracks $\sim 100 \mu \mathrm{m}$ wide were obtained as a result of a complete full factorial experiment. This experiment includes the finding of regression dependences of the track sizes from processing parameters. Experiment conditions and its results are given in [7]. Obtained parameters sets are shown in table 1. It was found that powder mass flow is the limiting factor of the thin-walled element width produced by cladding single tracks with a shift in the vertical direction. The parameters sets are divided into groups according to the mass flow.

Table 1. Influence of micro LMD modes on the thin-walled elements characteristics

\begin{tabular}{|l|l|l|l|l|l|l|}
\hline \multirow{2}{*}{ Set } & \multirow{2}{*}{$\begin{array}{l}\text { Powder mass } \\
\text { flow, } \mathrm{g} / \mathrm{min}\end{array}$} & \multirow{2}{*}{$\begin{array}{l}\text { Min. wall } \\
\text { width, } \mu \mathrm{m}\end{array}$} & \multirow{\mathrm{R}_{\mathrm{a}}}{*}{$\%$} & \multicolumn{3}{|l|}{ Surface roughness, $\mu \mathrm{m}$} \\
\cline { 5 - 7 } & & & $\mathrm{Ra}$ & $\mathrm{Rz}$ & $\mathrm{Rmax}$ \\
\hline 1 & $0,6 \ldots 1,25$ & $176 \pm 25$ & 0,25 & $1,9 \pm 0,2$ & $13 \pm 2$ & $24 \pm 2$ \\
\hline 2 & $0,15 \ldots 0,6$ & $140 \pm 20$ & 0,38 & $1,5 \pm 0,2$ & $8 \pm 2$ & $12 \pm 2$ \\
\hline 3 & $<0,15$ & $100 \pm 20$ & 0,47 & $1,3 \pm 0,2$ & $7 \pm 2$ & $8 \pm 2$ \\
\hline
\end{tabular}

With increasing powder mass flow the range of micro LMD variation parameters widens (power and step $\Delta \mathrm{z}$ ). And with z-increment increasing the wall width and relative arithmetic average surface roughness are increased (Fig.2). The decrease in mass flow ( $F_{\text {pow }}$ $<1.25 \mathrm{~g} / \mathrm{min})$ and the laser power $(\mathrm{P}<120 \mathrm{~W})$ have a similar effect: the parameter window variation narrows, the upper edge linearity deviation profile grows (Figure 3). The magnitude of this deviation increases with the number of layers (Figure 4). Parameters set\#1 allow to produce walls with a minimum width of $176 \pm 25 \mu \mathrm{m}$ and aspect ratio of 20.
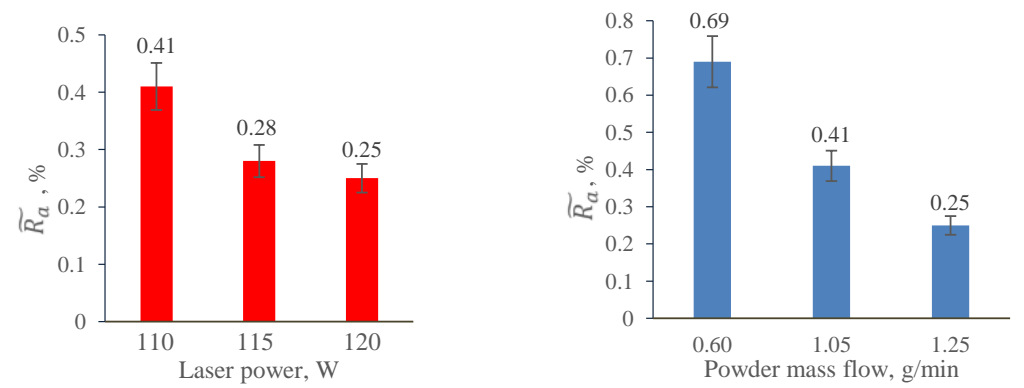

Fig. 3. Effect of laser power (left) and feed rate (right) on the wall upper edge linearity (set \#1). 
In parameters set \#2 the laser power varying window narrows $(105 \ldots 110 \mathrm{~W})$. The wall width decreases with increasing scanning velocity. At the velocity more than $12 \mathrm{~m} / \mathrm{min}$, the upper edge linearity is degraded (Fig. 4). To stabilize the process, further parameters miniaturization is required (transition to the parameters set \#3). Walls with a minimum width of $140 \pm 20 \mu \mathrm{m}$ can be produced using parameters set \#2.

In case of set \#3 the LMD parameters reach extreme values: scanning speed is up to $14 \mathrm{~m} / \mathrm{min}$, laser power - below $105 \mathrm{~W}$, powder mass flow - less than $0.15 \mathrm{~g} / \mathrm{min}$. The step $\Delta \mathrm{z}$ have to be reduced lower than $10 \mu \mathrm{m}$, when the powder mass flow is $<0.125 \mathrm{~g} / \mathrm{min}$. It can not be realized in a laboratory system. Set \# 3 allow to increase the resolution with a drastic deterioration of the upper edge linearity.

$3 \mathrm{D}$ images of the walls produced with parameters set \#2 are shown in Figure 5. For process stability reasons parameters sets \#1, \#2 (Table 2) are recommended.

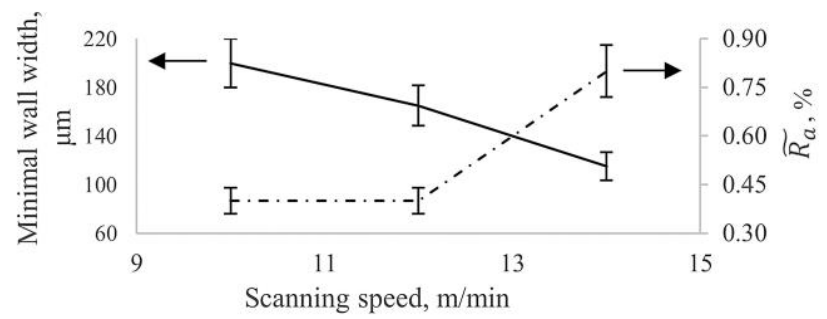

Fig. 4. Scanning velocity effect on the minimal wall width and on the upper edge linearity (set \#2).

Table 2. Micro LMD parameter set of AlSi30 powder during manufacturing small-sized products

\begin{tabular}{|l|l|l|l|l|}
\hline $\begin{array}{l}\text { Parameter } \\
\text { set }\end{array}$ & $\begin{array}{l}\text { Powder mass } \\
\text { flow, g/min }\end{array}$ & Power, W & $\begin{array}{l}\text { Scanning } \\
\text { velocity, m/min }\end{array}$ & $\begin{array}{l}\text { z-increment } \Delta \mathrm{z}, \\
\mu \mathrm{m}\end{array}$ \\
\hline 1 & $0,6 \ldots 1,25$ & $110 \ldots 120$ & $8 \ldots 12$ & $30 \ldots 50$ \\
\hline 2 & $0,15 \ldots 0,6$ & $105 \ldots 110$ & $10 \ldots 14$ & $20 \ldots 25$ \\
\hline
\end{tabular}
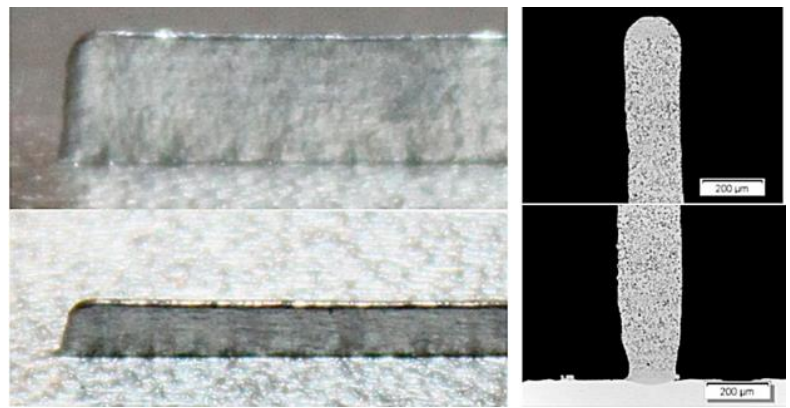

Fig. 5. Thin-walled objects produced by micro LMD of AlSi30 powder (parameter set \#2)

\subsection{Lattice structure}

Lattice structure was produced by micro LMD of AlSi30 powder (Ошибка! Источник ссылки не найден.). To minimize the material storage effect at the scanning path point of intersection the preferred $\Delta \mathrm{z}$-increment value is chosen. Shift in the vertical direction is made after every second layer. Lattice structures can be used to control the surface 
roughness and its aerodynamic and hydrodynamic properties during the flow through a liquid or gas stream and to ensure adhesion in applying thermal spray coatings.

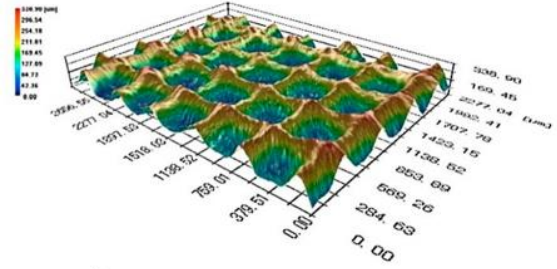

a) b)

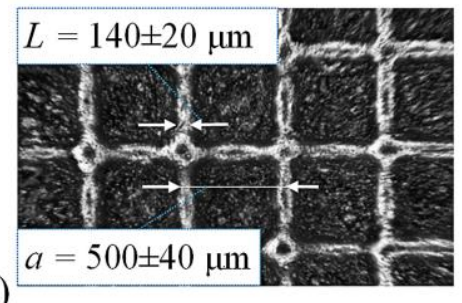

Fig. 6. Lattice structure, produced by micro LMD: a - 3D-view, b - top view (parameters set \#2).

\section{Conclusions}

Experimental data were obtained, that have significant importance to micro LMD development of Al-matrix composites (AMCs). AlSi30 powders were used as clad material, which thermal-physical properties can be estimated with sufficient reliability. For this reason obtained data can be used to validate computational models of heat transport during micro LMD.

The influence of the powder particle size and the cladding parameters on the minimal width and the quality of the fabricated thin walls was investigated.

The thin walls with the minimal width of $140 \mu \mathrm{m}$ and surface roughness $\mathrm{Ra} 1,5 \mu \mathrm{m}$ were generated.

Laser micro cladding potential to manufacture lattice-shaped structures of Al-matrix composites was demonstrated. Fabricated thin-wall structures can have application in different fields e.g. aviation, automotive and tooling industries.

The work is performed with financial support of the Ministry of Education and Science of Russian Federation within the framework of state assignment № 11. 1267. 2017 / ПЧ.

\section{References}

1. F. Brueckner, M. Riede and S. Nowotny, Laser Tech. J., 1, 29-31 (2013).

2. T. Jambor , K.Wissenbach , Reparatur und Verschleißschutz von Mikrowerkzeugen durch automatisiertes Mikro-Laserstrahl-Auftragschweißen. in TAW-Symposium: Termisches Beschichten mit laserbasierten Fertigungsverfahren. Dresden, Germany (2006).

3. St. Kaierle, A. Barroi, Ch. Noelke, J. Hermsdorf, L. Overmeyer, H. Haferkamp, Physics Procedia, 39, 1-10 (2012).

4. Y.A.Melnik, T.V. Tarasova, G.O.Gvozdeva, S.Nowotny, Mechanics and industry, 17, 1-7 (2016).

5. D. Geldart, Powder technology, 7, 285-292 (1973).

6. H. Becker, Verfahrensentwicklung und theoretische Betrachtungen zum lasergestützten 3D-Mikro-Auftragschweißen : Verfahrensentwicklung und theoretische Betrachtungen zum lasergestützten 3D-Mikro-Auftragschweißen, Universität Hannover, 127 (2004).

7. T.V.Tarasova, G.O.Gvozdeva, S.Nowotny, R.R. Ableyeva, Yu.E.Dolzhikova, APRN Journal of Engineering and Applied Science, V.13, №4, 1438-1442 (2018). 